\title{
A High-Torque Magnetless Axial-Flux Doubly-Salient Machine for In-Wheel Direct Drive Applications
}

\author{
Christopher H. T. Lee, K. T. Chau, Fellow, IEEE, Chunhua Liu, T. W. Ching, and Fuhua Li \\ Department of Electrical and Electronic Engineering, The University of Hong Kong, Hong Kong, China
}

In this paper, the concept of DC-field (DC) excitation is newly incorporated into the axial-flux doubly-salient (AF-DS) machine, leading to create the new magnetless AF-DSDC machine. With the external field excitation, the proposed machine not only can enjoy its improved torque density, but also the flux-weakening capability for the wide-speed range operation. With these characteristics, the AF-DSDC is favorable for the in-wheel direct drive application. Particularly, the proposed machine is designed and compared based on the requirement of a typical passenger electric vehicle (EV). To have a better illustration, a radial-flux (RF) DSDC machine is also designed under the fair environment. The corresponding performances of both machines are analyzed by using the $2 \mathrm{D}$ and $3 \mathrm{D}$ finite element method (FEM).

Index Terms-Magnetless machine, axial-flux, DC-field excitation, doubly-salient, in-wheel direct drive.

\section{INTRODUCTION}

$\mathrm{W}$ ITH ever increasing concerns on energy efficiency and hence environmental protection, the development of the electric machines has been speeding up [1]. In general, the electric machines have to offer high efficiency, high power density, high controllability, wide-speed range, and maintenance-free operation $[2,3]$. To achieve these goals, the permanent-magnet (PM) machines have been actively developed. However, in recent years, the supply of the PM materials is limited and fluctuating, leading to the soared material cost [4]. Thus, the advanced magnetless radial-flux doubly-salient (RF-DS) machines are becoming attractive [5]. Compared with the PM machines, the magnetless RF-DS machines take the definite merit of low material cost, but suffer from relatively low torque density.

The axial-flux (AF) DS machine, which employs the radial length as active part for torque production, can improve the torque density as compared with its RF counterpart [6, 7], and it is particular favorable for the application of the in-wheel motor drive. However, similar as the RF-DS machine, the AFDS machine uses only half of its torque producing zone, resulting with degraded torque performances. Meanwhile, the concept of DC-field (DC) excitation, which allows the RF-DS to utilize the remaining torque zones, was proposed $[8,9]$, but the possibility for implementing the DC winding into the AFDS machine has rarely addressed yet.

The purpose of this paper is to newly incorporate the DC winding into the AF-DS machine, hence creating the new AFDSDC machine, purposely for the application of in-wheel direct drive. To achieve a better illustration purpose, a RFDSDC machine is also designed. The design criteria and operating principles of the two magnetless machines will be discussed. Their performances will be analyzed by using the 2D and 3D finite element methods (FEM), and then quantitatively compared with the requirements of the typical passenger electric vehicle (EV) applications.

Manuscript received March 5, 2014. Corresponding author: K.T. Chau (e-mail: ktchau@eee.hku.hk).

Digital Object Identifier inserted by IEEE

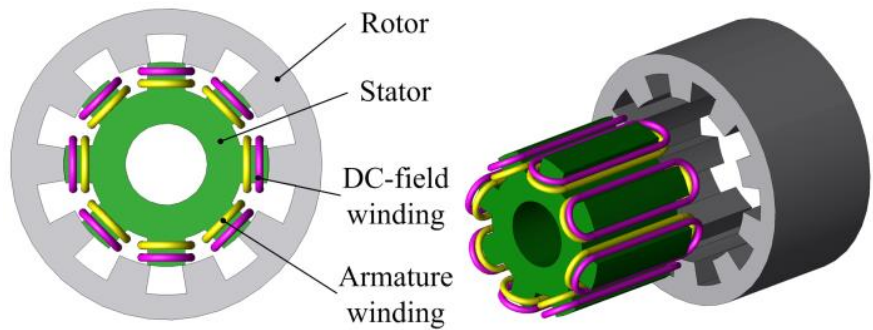

(a)
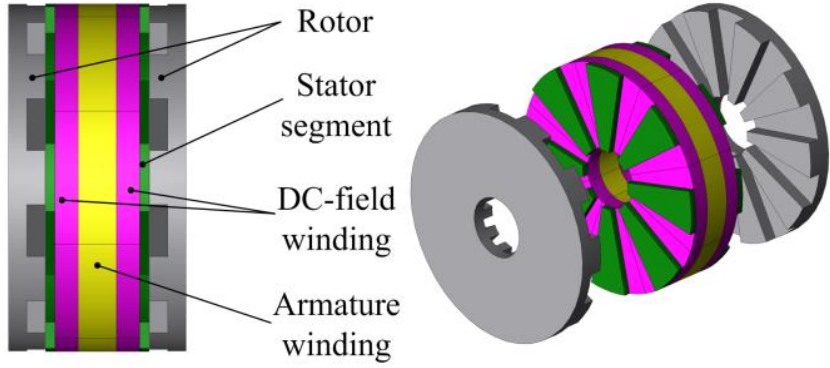

(b)

Fig. 1. Proposed machines: (a) RF-DSDC. (b) AF-DSDC.

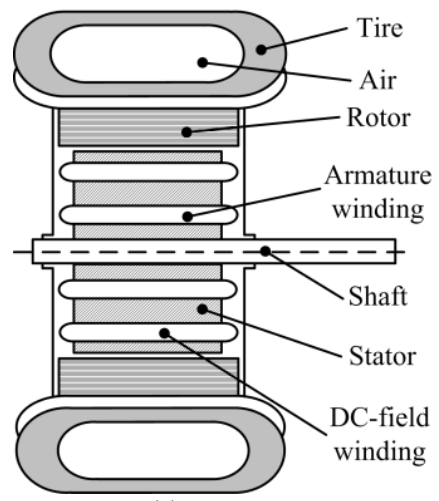

(a)

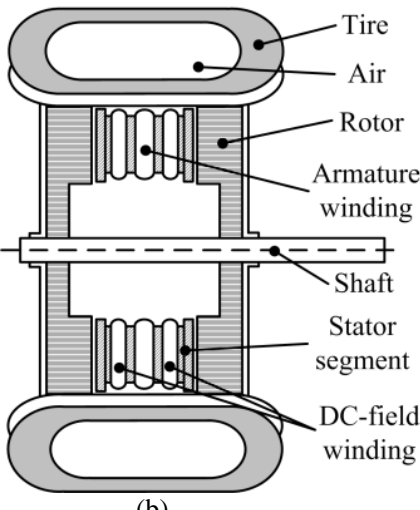

(b)
Fig. 2. In-wheel direct drive structures: (a) RF-DSDC. (b) AF-DSDC.

\section{PROPOSED MACHINES}

Fig. 1 shows the topologies of the two magnetless machines, namely the 8/10-pole RF-DSDC machine, and the 8/10-pole AF-DSDC machine. The RF-DSDC machine adopts the inner-stator outer-rotor structure, while the AF-DSDC 
adopts the sandwiched-stator sided-rotor structure. With suitable dimensions, both machines can mount its rotors to the tires directly. For instance, one of the most common wheel sizes is 195/65 R15, denoting the axial length is $195 \mathrm{~mm}$ and the rim diameter is 15 inch, ie: $381 \mathrm{~mm}$. Hence, the two machines are purposely designed with this dimension such that both of them can be implemented into in-wheel motor drive system instinctively, as shown in Fig. 2. Meanwhile, based on the requirements of a typical passenger EV [2], the targeted specifications of the machines are listed in Table I.

The proposed AF-DSDC adopts the modular stator construction method [7], such that the individual stator segments are constructed independently. Then, all the stator segments are consolidated together to form the yokeless stator. With the reduction of the stator yoke, the proposed AF-DSDC machine can further improve its torque density and minimize its material cost. Furthermore, the yokeless stator structure enables more spacing for the winding accommodations.

Since the AF-DSDC machine is derived from the RF-DSDC machine, its design equations such as the pole arrangement [9] can be extended from that of the profound RF-DSDC machine. Thus, the pole arrangements for both the RF-DSDC and AF-DSDC are governed by:

$$
\left\{\begin{array}{l}
N_{s}=2 m k \\
N_{r}=N_{s} \pm 2 k
\end{array}\right.
$$

where $N_{s}$ is the number of stator poles, $N_{r}$ the rotor poles, $m$ the armature phases and $k$ is any integer. By selecting $m=4$, and $k=1$, this ends up with $N_{s}=8, N_{r}=10$ and comes up with the proposed structure of the two machines.

To have a fair comparison, the machine dimensions, namely the radial outside diameters, radial inside diameters, axial stack lengths, and airgap lengths are set equal. In addition, the pole arcs, pole heights, slot-fill factors, and current densities are designed in such a way that the magnetic saturation and hence the core losses can be minimized.

\begin{tabular}{ll}
$\begin{array}{r}\text { TABLE I. TARGET MOTOR SPECIFICATIONS FOR } \\
\text { TYPICAL EV APPLICATION }\end{array}$ \\
\hline \hline Item & Value \\
\hline Peak DC voltage & $360 \mathrm{~V}$ \\
Rated power & $3.1 \mathrm{~kW}$ \\
Rated torque & $100 \mathrm{Nm}$ \\
Constant-torque operation & $0-300 \mathrm{rpm}$ \\
Constant-power operation & $300-900 \mathrm{rpm}$ \\
Peak power & $140 \%$ for $60 \mathrm{~s}$ \\
Wheel & $195 / 65 \mathrm{R} 15$ \\
\hline \hline
\end{tabular}

\section{OPERATING PRINCIPLE}

The proposed AF-DSDC machine adopts the concentrated winding arrangement on the sandwiched-stator in a way that the DC flux-linkages flow along the two sided-rotors via the stator segment as shown in Fig. 3. In addition, it is expected that the flux-linkages vary according to the relative statorrotor position. Hence, under this winding arrangement, both sided-rotors can be operated in the same sense with the single set of 4-phase armature winding.

With the DC-field excitations, both machines can operate with the bipolar rectangular current operation. When the fluxlinkage is increasing, a positive rectangular current $I_{\text {rect }}$ is applied to produce a positive torque. Meanwhile, a negative rectangular current $-I_{\text {rect }}$ is applied when the flux-linkage is decreasing and the torque produced is also positive. The operating waveforms of the machines are shown in Fig. 4. Under this operation, all the torque-producing zones are utilized and the torque ripple can be suppressed. Each phase performs $90^{\circ}$ conduction with $\theta_{2}-\theta_{1}=\theta_{4}-\theta_{3}=90^{\circ}$ and the developed torques of these two machines are shown as:

$$
\begin{aligned}
& T_{R F-D S D C}=\frac{1}{2 \pi} \int_{0}^{2 \pi}\left(I_{\text {rect }} \frac{d \psi_{R F-D S D C}}{d \theta}+\frac{1}{2} I_{\text {rect }}^{2} \frac{d L_{R F-D S D C}}{d \theta}\right) d \theta \\
& T_{A F-D S D C}=\frac{1}{2 \pi} \int_{0}^{2 \pi}\left(I_{\text {rect }} \frac{d \psi_{A F-D S D C}}{d \theta}+\frac{1}{2} I_{\text {rect }}^{2} \frac{d L_{A F-D S D C}}{d \theta}\right) d \theta
\end{aligned}
$$

where $\Psi_{R F-D S D C}$ and $\Psi_{A F-D S D C}$ are the flux-linkages of the RFDSDC and AF-DSDC machines, respectively; and $L_{R F-D S D C}$ and $L_{A F-D S D C}$ are their self-inductances. It should be noted that the developed torques are mainly contributed by DC-field torque components, whereas the reluctance torque components resulted as an averaged zero value [9].

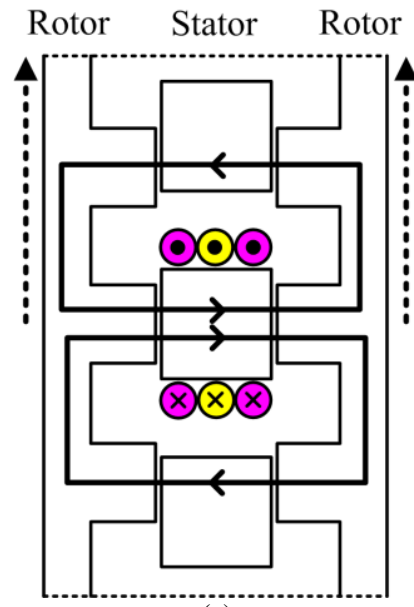

(a)

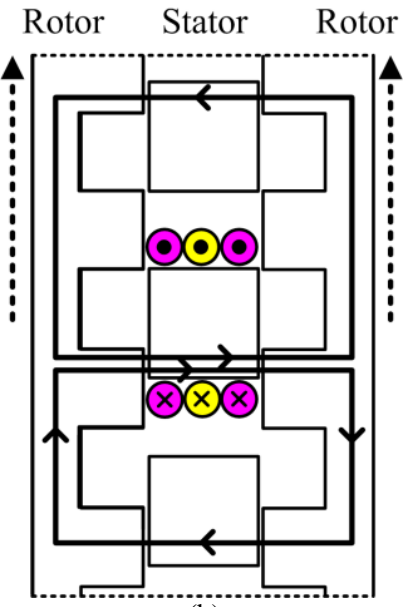

(b)
Fig. 3. Flux pattern of AF-DSDC: (a) Position 1. (b) Position 2.

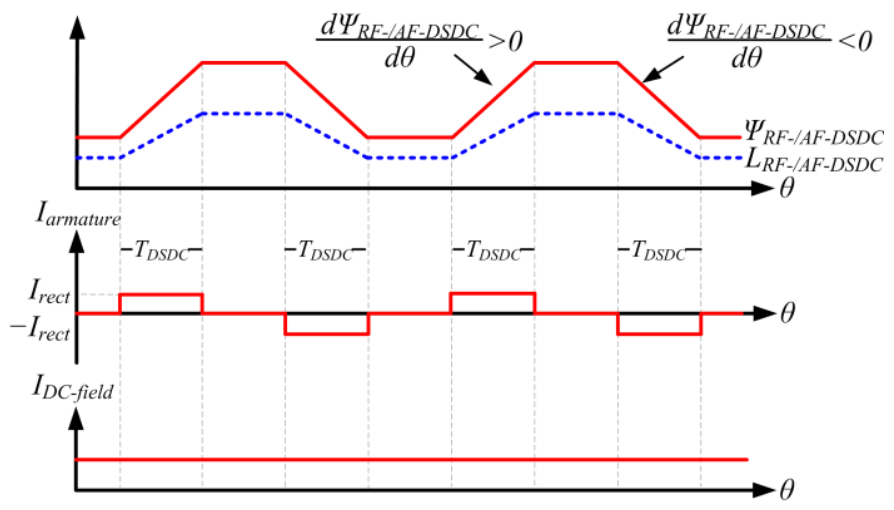

Fig. 4. Theoretical operating waveform.

TABLE II. MACHINE KEY DATA

\begin{tabular}{lll}
\hline \hline & RF-DSDC & AF-DSDC \\
\hline Radial outside diameter & $381.0 \mathrm{~mm}$ & $381.0 \mathrm{~mm}$ \\
Radial inside diameter & $100.0 \mathrm{~mm}$ & $100.0 \mathrm{~mm}$ \\
Airgap length & $0.5 \mathrm{~mm}$ & $0.5 \mathrm{~mm}$ \\
Axial stack length & $195.0 \mathrm{~mm}$ & $195.0 \mathrm{~mm}$ \\
Rotor pole number & 10 & 10 \\
Stator pole number & 8 & 8 \\
No. of phases & 4 & 4 \\
Slot-fill factor & $60 \%$ & $60 \%$ \\
No. of armature turns & 60 & 120 \\
\hline \hline
\end{tabular}




\section{PERformance Analysis}

All the two magnetless machines are analyzed under the fair environment and the key design data of the machines are listed in Table II. By using the 2D- and 3D-FEM, all machine performances can be simulated and then quantitatively compared. The no-load magnetic field distribution of the AFDSDC is shown in Fig. 5. JMAG-Designer is employed for performing the FEM. Each simulation process takes less than an hour for 2D-FEM, while more than 10 hours for 3D-FEM based on a high-performance PC.

First of all, the flux-linkages of RF-DSDC and AF-DSDC are shown in Fig. 6. It can be seen that both flux-linkages are well balanced among four phases without noticeable distortion. These confirm that the design data of these two machines are correct. In addition, the results confirm that the proposed winding arrangement enables the AF-DSDC to achieve the same flux-linkage pattern as the conventional one.

Secondly, the no-load electromotive forces (EMFs) of the RF-DSDC and AF-DSDC under the DC-field excitation of 5 $\mathrm{A} / \mathrm{mm}^{2}$ at base speed $300 \mathrm{rpm}$ are shown in Fig. 7. The results show that both machines obtain the trapezoidal patterns, which are suitable for the rectangular current conduction schemes. Meanwhile, the no-load EMFs produced by AF-DSDC are larger than those by RF-DSDC are. Hence, it is expected that the power level of the AF-DSDC should be higher.

In the third place, the airgap flux density distributions of both machines are calculated as shown in Fig. 8. These show that both machines obtain the same airgap flux pattern. For the AF-DSDC, because the flux flows along the two sided-rotors via the sandwiched-stator, the flux patterns of the two airgaps are symmetrical, but in opposite directions.

Fourthly, the output torque waveforms of the RF-DSDC and AF-DSDC machines are simulated as shown in Fig. 9(a) and Fig. 9(b), respectively. It can be observed that the rated average torques of the RF-DSDC, of the AF-DSDC machines are $80.6 \mathrm{Nm}$ and $161.8 \mathrm{Nm}$, respectively. Compared with the RF-DSDC machine, the torque enhancement of the AF-DSDC is $100.7 \%$. It can also be observed that the torque ripples of the RF-DSDC and AF-DSDC machines are 33.5\% and 19.7 $\%$, respectively, which are comparable to the conventional RF machines [3]. The high torque density and low torque ripple value offered by the AF-DSDC machine are particularly favorable for the in-wheel direct drive applications. Meanwhile, the cogging torques of the RF-DSDC and AFDSDC machines are shown in Fig. 10(a) and Fig. 10(b), respectively. It can be shown that the peak amplitudes of the cogging torques of the RF-DSDC and AF-DSDC are $10.7 \mathrm{Nm}$ and $19.6 \mathrm{Nm}$, respectively. These values are still acceptable, which are only $13.3 \%$ and $12.1 \%$ of their rated torques.

Finally, the flux-weakening performances of the RF-DSDC and AF-DSDC are simulated and shown in Fig. 11(a) and Fig. 11(b), respectively. The DC-field excitations of both machines can be independently controlled easily. Hence, both machines can obtain high flux-weakening capabilities to achieve widespeed range operations, which is one of the major criteria for the in-wheel motor drive application. With the $0.5 \mathrm{~A} / \mathrm{mm}^{2}$ field excitations, the operating speeds of the RF-DSDC and AF-DSDC are $1691 \mathrm{rpm}$ and $1517 \mathrm{rpm}$, respectively. These confirm the proposed machines can fulfill the requirements of the normal EV applications.
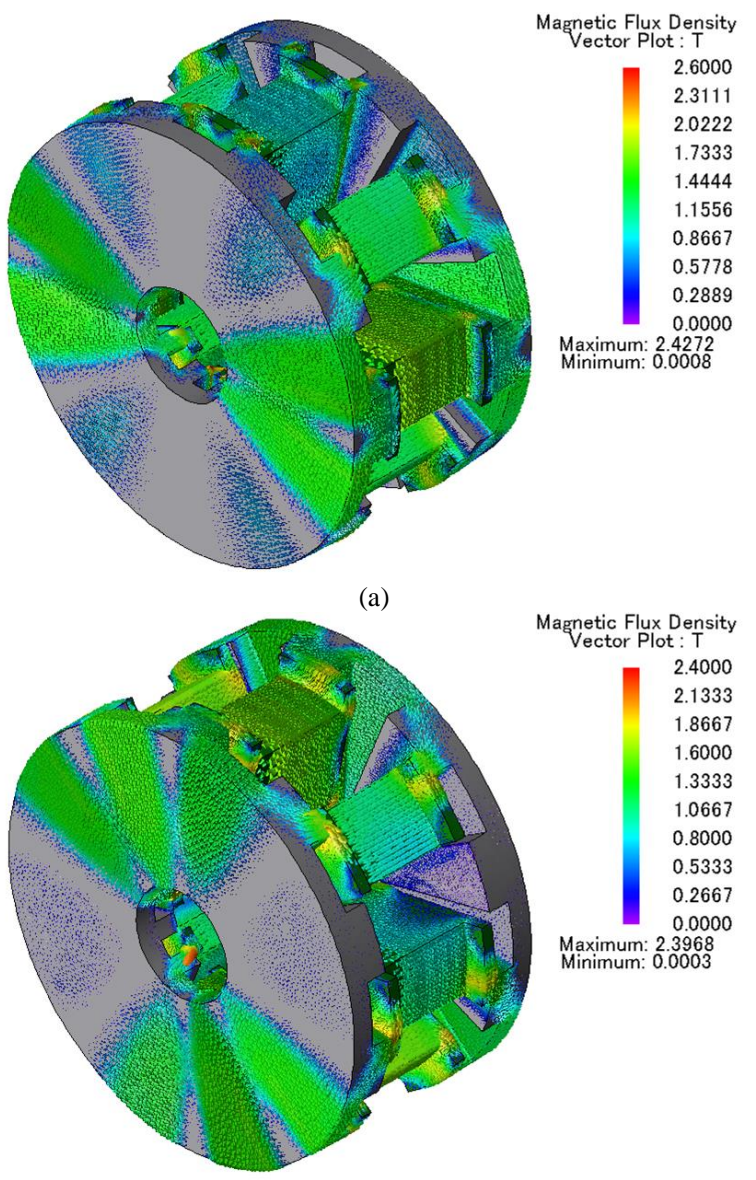

(b)

Fig. 5. No-load magnetic field distribution: (a) Position 1. (b) Position 2.

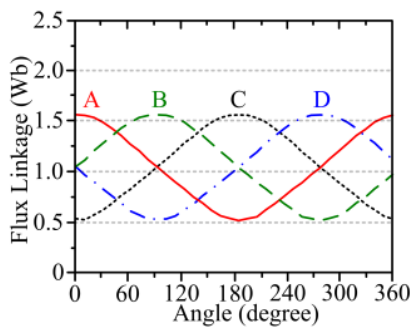

(a)

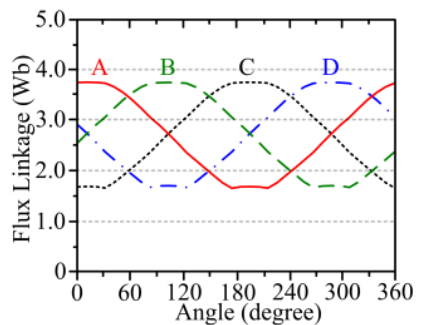

(b)
Fig. 6. Flux linkages: (a) RF-DSDC. (b) AF-DSDC.

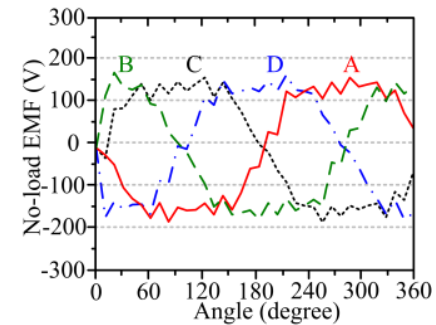

(a)

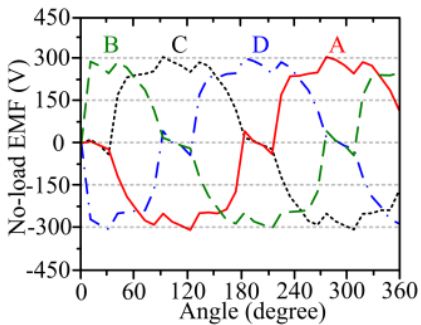

(b)
Fig. 7. No-load EMFs at DC-field of $5 \mathrm{~A} / \mathrm{mm}^{2}$ : (a) RF-DSDC. (b) AF-DSDC. 


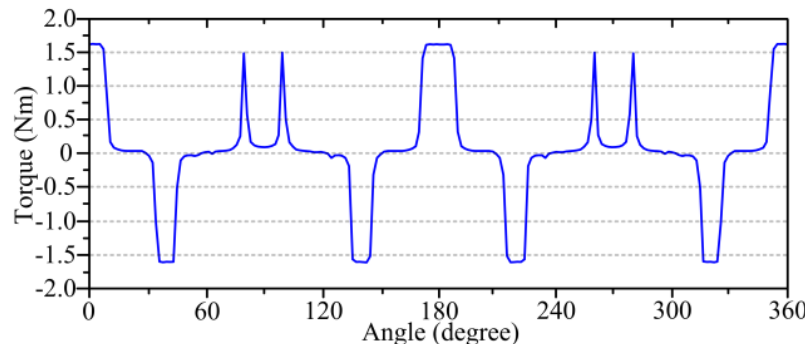

(a)

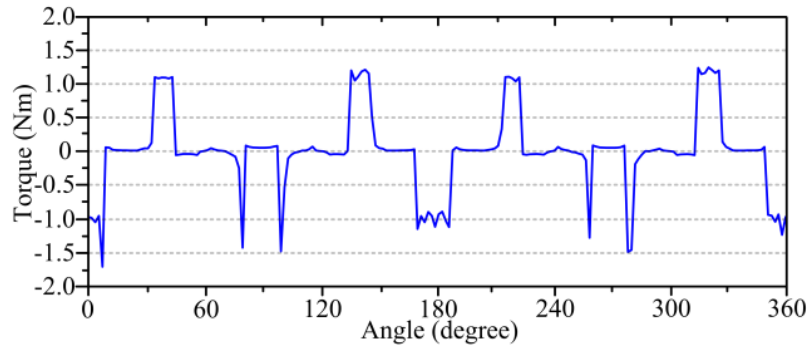

(b)

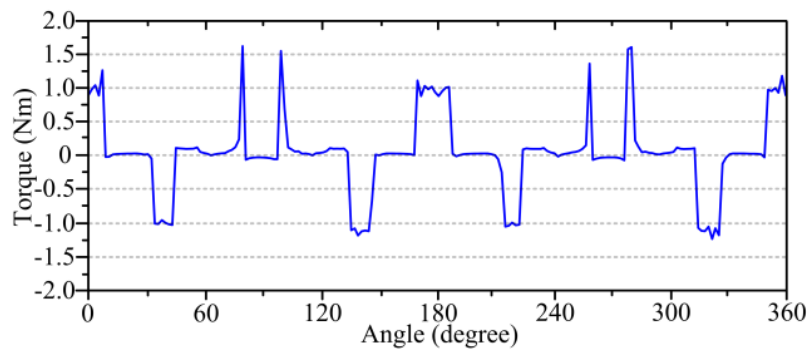

(c)

Fig. 8. Airgap flux densities: (a) RF-DSDC. (b) Left airgap of AF-DSDC. (c) Right airgap of AF-DSDC.

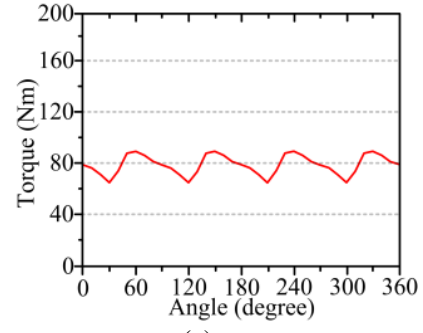

(a)

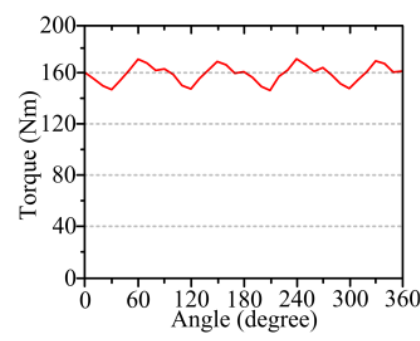

(b)
Fig. 9. Rated torque waveforms: (a) RF-DSDC. (b) AF-DSDC.

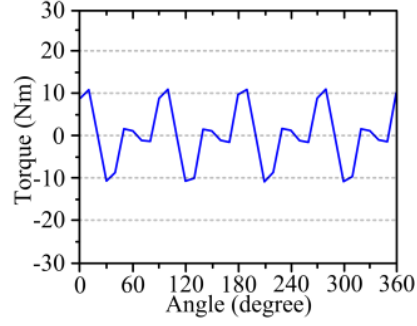

(a)

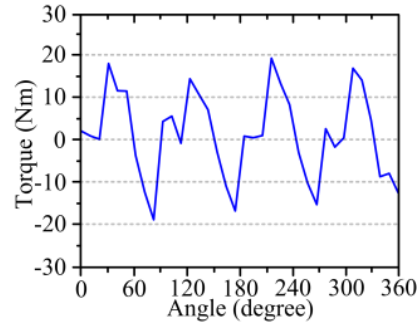

(b)
Fig. 10. Cogging torque waveforms: (a) RF-DSDC. (b) AF-DSDC.

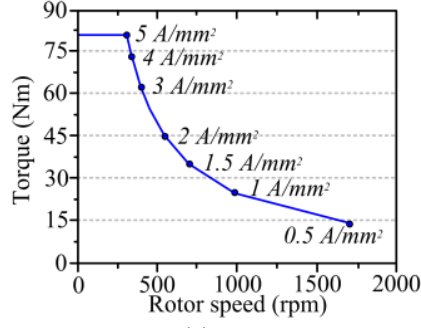

(a)

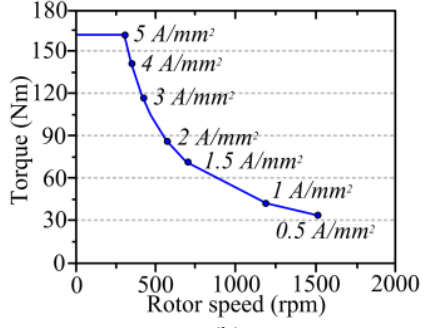

(b)
Fig. 11. Torque-speed characteristics: (a) RF-DSDC. (b) AF-DSDC.
TABLE III. MACHINE PERFORMANCE COMPARISON

\begin{tabular}{lll}
\hline \hline & RF-DSDC & AF-DSDC \\
\hline Power & $2500 \mathrm{~W}$ & $5050 \mathrm{~W}$ \\
Base speed & $300 \mathrm{rpm}$ & $300 \mathrm{rpm}$ \\
Field excitation & $5 \mathrm{~A} / \mathrm{mm}^{2}$ & $5 \mathrm{~A} / \mathrm{mm}^{2}$ \\
No-load EMF & $150 \mathrm{~V}$ & $305 \mathrm{~V}$ \\
Rated torque & $80.6 \mathrm{Nm}$ & $161.8 \mathrm{Nm}$ \\
Torque enhancement & $\mathrm{N} / \mathrm{A}$ & $100.7 \%$ \\
Torque density & $4920 \mathrm{Nm} / \mathrm{m}^{3}$ & $9850 \mathrm{Nm} / \mathrm{m}^{3}$ \\
Cogging torque & $10.7 \mathrm{Nm}$ & $19.6 \mathrm{Nm}$ \\
Torque ripple & $33.5 \%$ & $19.7 \%$ \\
\hline \hline
\end{tabular}

\section{CONCLUSION}

In this paper, two magnetless DS machines, namely the RFDSDC and AF-DSDC have been analyzed and quantitatively compared, while the comparisons are summarized in Table III. By applying the radial area as active part for torque production, the AF-DSDC exhibits better torque performances than its RF counterpart does. To be specific, the AF-DSDC can produce satisfactory power and torque densities compared with the PM machines do [3]. Because of the ever increasing cost and limited supply of the PM material, the magnetless machines are becoming more and more promising. Meanwhile, with the independent DC-field windings, the proposed machines both enjoy the flux-weakening capability for the wide-speed range operations. Based on the analysis and comparisons, the proposed AF-DSDC can fulfill all the requirements for the inwheel direct drive application, while the RF-DSDC fails in some tasks from the expectations.

\section{ACKNOWLEDGMENT}

This work was supported by a grant (Project No. HKU710612E) from the Hong Kong Research Grants Council, Hong Kong Special Administrative Region, China.

\section{REFERENCES}

[1] K. T. Chau, W. Li, and C. H. T. Lee, "Challenges and opportunities of electric machines for renewable energy," Prog. Electromagn. Res. B, vo. 42, pp. 45-74, 2012.

[2] R. Cao, C. Mi, and M. Cheng, "Quantitative comparison of fluxswitching permanent-magnet motors with Interior permanent magnet motor for EV, HEV, and PHEV applications," IEEE Trans. Magn., vol. 48, no. 8, pp. 2374-2384, Dec. 2008.

[3] M. Cheng, W. Hua, J. Zhang, and W. Zhao, "Overview of statorpermanent magnet brushless machines," IEEE Trans. Ind. Electron, vol. 58, no. 11, pp. 5087-5101, Nov. 2011.

[4] M. Chen, K. T. Chau, W. Li, and C. Liu, "Cost-effectiveness comparison of coaxial magnetic gears with different magnet materials," IEEE Trans. Magn. (To be appeared)

[5] C. H. T. Lee, K. T. Chau, C. Liu, D. Wu, and S. Gao, "Quantitative comparison and analysis of magnetless machine with reluctance topologies," IEEE Trans. Magn., vol. 49, no. 7, pp. 3969-3972, Jul. 2013.

[6] F. Profumo, Z. Zhang, and A. Tenconi, "Axial flux machines drives: A new viable solution for electric cars," IEEE Trans. Ind. Electron, vol. 44, no. 1, pp. 29-45, Feb. 1997.

[7] H. Vansompel, P. Sergeant, L. Dupre, and A. V. D. Bossche, "Axial-flux PM machines with variable air gap," IEEE Trans. Ind. Electron, vol. 62, no. 2, pp. 730-737, Feb. 2014.

[8] Y. Fan, K. T. Chau, and S. Niu, "Development of a new brushless doubly fed doubly salient machine for wind power generation," IEEE Trans. Magn., vol. 44, no. 10, pp. 3455-3457, Oct. 2006.

[9] C. H. T. Lee, K. T. Chau, and C. Liu, "Electromagnetic design and analysis of magnetless double-rotor dual-mode machines," Prog. Electromagn. Res., vol. 142, pp. 333-351, 2013. 